\title{
The Role of Parental Achievement Goals in Predicting Autonomy-Supportive and Controlling Parenting
}

\author{
Geneviève A. Mageau ${ }^{1}$ (D) Julien S. Bureau ${ }^{1} \cdot$ Francis Ranger $^{1} \cdot$ Marie-Pier Allen $^{1}$ • \\ Bart Soenens $^{2}$
}

Published online: 11 December 2015

(c) Springer Science+Business Media New York 2015

\begin{abstract}
Although autonomy-supportive and controlling parenting are linked to numerous positive and negative child outcomes respectively, fewer studies have focused on their determinants. Drawing on achievement goal theory and self-determination theory, we propose that parental achievement goals (i.e., achievement goals that parents have for their children) can be mastery, performance-approach or performance-avoidance oriented and that types of goals predict mothers' tendency to adopt autonomysupportive and controlling behaviors. A total of 67 mothers (aged 30-53 years) reported their goals for their adolescent (aged 13-16 years; $19.4 \%$ girls), while their adolescent evaluated their mothers' behaviors. Hierarchical regression analyses showed that parental performance-approach goals predict more controlling parenting and prevent acknowledgement of feelings, one autonomy-supportive behavior. In addition, mothers who have mastery goals and who endorse performance-avoidance goals are less likely to use guilt-inducing criticisms. These findings were observed while controlling for the effect of maternal anxiety.
\end{abstract}

Keywords Achievement goals · Autonomy support · Controlling parenting $\cdot$ Mastery $\cdot$ Performance

Geneviève A. Mageau

g.mageau@umontreal.ca

1 Département de psychologie, Université de Montréal, C.P. 6128, Succursale Centre-Ville, Montréal, QC H3C 3J7, Canada

2 Department of Developmental, Personality and Social Psychology, Ghent University, Ghent, Belgium

\section{Introduction}

Autonomy-supportive and controlling parenting have been repeatedly linked to children's social, academic and psychological adjustment (Grolnick and Pomerantz 2009; Joussemet et al. 2008a; Moreau and Mageau 2013). However, fewer studies have focused on the determinants of these parenting dimensions. This is unfortunate because gaining insight into the obstacles and facilitating factors of more autonomy-supportive, and less controlling, parenting behaviors is important to assist parents in fostering their children's need for autonomy.

Self-determination theory proposes that human beings have an innate and universal need for autonomy, that is, the need to feel a sense of agency and ownership of their behaviors (Deci and Ryan 2000). Children feel autonomous when they are intrinsically motivated or when they have internalized or taken over societal values as their own. They are then said to act because of self-endorsed (or selfdetermined) reasons, and this can occur even when behaviors are initially prompted externally (Joussemet et al. 2014; Koestner et al. 1984). Typically, parental autonomy support has been operationalized with three behaviors: providing a meaningful rationale for limits and demands (e.g., teeth need brushing each day to avoid cavities), giving choices within these limits (e.g., do you want to brush your teeth now or after the story?), and acknowledging the child's feelings (e.g., it's true, teeth brushing is not always fun; Deci et al. 1994; Grolnick and Ryan 1989; Koestner et al. 1984). More generally, autonomy-supportive parents are empathic, descriptive (i.e., informational instead of evaluative) and they provide opportunities for active participation (e.g., in decisions making or in problem solving) instead of being intrusive, dominating and pressuring (Grolnick and Pomerantz 2009). 
Autonomy support is thus different from permissiveness because it can be combined (and ideally is combined) with parental provision of structure, such as limit settings (Koestner et al. 1984) or rule enforcement (Lessard et al. 2015). Parental autonomy support has been linked to positive outcomes at different developmental stages (see Joussemet et al. 2008a; Moreau and Mageau 2013, for reviews) such as a more secure attachment style (Whipple et al. 2011) and better executive functioning (Bernier et al. 2010) in toddlers, higher social and academic adjustments in elementary school children (Bronstein et al. 1996; Grolnick and Ryan 1989; Joussemet et al. 2005), and higher well-being (Downie et al. 2007; Niemiec et al. 2006; Soenens et al. 2007), more life satisfaction (Sheldon et al. 2009) and less health-risk behaviors (Williams et al. 2000) in adolescence. Importantly, research based on experimental designs has also shown that autonomy-supportive limit-setting facilitates internalization of societal values and expectations compared to controlling conditions, while preserving intrinsic motivation and creativity (Joussemet et al. 2004; Koestner et al. 1984).

The opposite of autonomy support in terms of its psychological significance for the child is autonomy-thwarting or controlling parenting (Grolnick and Pomerantz 2009; Soenens et al. 2007). One often examined type of controlling parenting is psychological control (Barber 1996). Controlling parenting is characterized by pressure, intrusion, and domination (Grolnick and Pomerantz 2009) and can be either externally (e.g., coercive threats) or internally controlling (e.g., conditional love, invalidation, shaming; Soenens and Vansteenkiste 2010). In the present study, controlling parenting is operationalized using both externally and internally controlling behaviors (i.e., threats, guilt inductions, and performance pressures; Mageau et al. 2015a). Controlling parenting has been linked to children's oppositional behaviors (Bronstein 1994), antisocial acts (Barber 1996; Conger et al. 1997; Herman et al. 1997; Joussemet et al. 2008b; Prinzie et al. 2010), and emotional self-regulation problems (Fabes et al. 2001). It also significantly predicts internalized problems (Fauber et al. 1990) such as childhood anxiety (Ballash et al. 2006; Rapee 1997; Wood et al. 2003), depression (Barber 1996; McCranie and Bass 1984; Miller et al. 1990; Soenens et al. 2008a, b), and lower self-esteem (Conger et al. 1997; Garber et al. 1997; Silk et al. 2003). Given the robust linkage between more autonomy-supportive (and less controlling) parenting and children's and adolescents' psychological adjustment (Joussemet et al. 2008a; Moreau and Mageau 2013), it is imperative to uncover the facilitating and impeding factors of these parenting behaviors.

Most studies that investigated the determinants of parenting have identified obstacles of autonomy-supportive behaviors or risk factors that lead parents to be more controlling. Parents who are perfectionists (Flett et al. 2002) or achievement oriented (Pomerantz and Eaton 2001), who feel anxious when they are apart from their children (Soenens et al. 2006), who hinge their self-esteem on their child's behavior (Grolnick et al. 2007), and who have a strong fear of failure (Elliot and Thrash 2004) were found to be more controlling than parents without these personal characteristics. At the contextual level, children who have a more difficult temperament (Pettit et al. 2001), are less achievement oriented (Pomerantz and Eaton 2001), or are less intrinsically motivated (Courneya and McAuley 1991) tend to elicit more control from their parents and other adults (Anderson et al. 1986). Stressful life events (Grolnick et al. 1996), lower socio-economic status (SES; Dodge et al. 1994), unemployment (McLoyd 1989), and perceived environmental threat (Gurland and Grolnick 2005) are yet other contextual factors associated with controlling parenting. At the situational level, Zussman (1980) showed that situational stress is related to controlling behaviors: Mothers who were asked to supervise their children in a moderately hazardous situation were more controlling when they were also preoccupied with an additional task.

In one of the few studies examining factors that can facilitate autonomy support in the parent-child relationship, Landry et al. (2008) found that mothers' trust that children's development proceeds in a natural and healthy way (i.e., organismic trust) is positively associated with mothers' autonomy-supportive practices. Studies conducted in other types of hierarchical relationships suggest that higher well-being (Stebbings et al. 2011) and viewing subordinates' abilities as reflecting efforts and practice instead of as being a personality trait (Leroy et al. 2007) could also facilitate more autonomy-supportive behaviors.

Taken together, these findings suggest that personal, contextual and situational pressures prevent parents from adopting autonomy-supportive behaviors and trigger more controlling parenting. When interpreting these findings, Grolnick (2003) proposed that pressures orient parents toward more outcome-focused goals, leading them to overlook their child's internal frame of reference and adopt more controlling parenting strategies. Although the hypothesis that parental goals influence parenting behaviors is widely shared, little research has specifically addressed this question (Dix 1992; Goodnow and Collins 1990; Grusec et al. 1997; Kuczynski 1984; Maccoby and Martin 1983). We know that parents who are made to focus on the outcome (by telling them that their children's memory of an event would be tested) are more controlling than parents who are encouraged to focus on the process (by telling them that their children's personal perspective of an event would be assessed; Cleveland et al. 2007). Kuczynski (1984) also found that mothers who were given 
a long-term compliance goal (by being told that their child would need to comply when alone) were more likely to use reasoning strategies than mothers who were given shortterm compliance goals (child would only need to comply in their presence). Finally, Dix (1992) proposed that goals differ in the extent to which they are parent-centered, empathic, and oriented toward socialization (Dix 1992; Grusec et al. 1997). Relations between parental goals and parenting behaviors can be investigated further by drawing on Elliot and Church (1997)'s achievement goal model, an influential theory in goal research.

In the achievement goal model, achievement goals concern competence development and achievement (Elliot and Church 1997). Applied to parenting, parental achievement goals are goals that parents have regarding the development and achievement of their children's own competence. Traditionally, achievement goals have been distinguished as a function of the way competence is evaluated (i.e., mastery vs. performance; Dweck 1986; Elliot et al. 2011; Nicholls 1984). A similar distinction is also made for parental achievement goals. Parents with parental mastery goals want their children to develop their competence and thus evaluate achievement using temporal comparisons (past vs. present performance). In contrast, parents who pursue performance goals work toward a demonstration of their children's competence as evaluated by social comparisons with their peers. In a pioneer study, Gonida and Cortina (2014) provided evidence that parental achievement goals may influence autonomy-support and controlling parenting. Specifically, results showed that the more parents endorsed mastery goals when helping their children with their homework, the more they reported engaging in autonomy-supportive behaviors, and the more parents had performance goals during homework the more they reported using controlling strategies. However, because all measures were based on parent reports, these findings were not free from potential common variance bias.

Furthermore, goal research has established that goals also differ in their motivational orientation (i.e., approach vs. avoidance; Elliot 1999; Elliot and Harackiewicz 1996; Elliot et al. 2011). People can thus be oriented toward achieving high levels of competence/performance or they can focus instead on avoiding failure. Applied to the performance goals in the parenting context, parents with performance-approach goals want their children to exhibit higher levels of performance than their peers, while parents with performance-avoidance goals want to avoid situations where their children would appear incompetent compared to their peers. The distinction between performance-approach and performance-avoidance goals has proved particularly important when predicting learning outcomes. For example, while performance-avoidance goals are consistently associated with negative learning outcomes (e.g., surface processing, test anxiety, lower GPA, and avoidance of help seeking; see Moller and Elliot 2006, for a review), performance-approach goals have yielded a more complex pattern of associations. Performance-approach goals are related to both positive (e.g., higher performance) and less desirable (e.g., more surface processing and avoidance of help seeking) outcomes. Given the differential outcomes of performance-approach and performance-avoidance goals, their influence on parenting may also greatly differ.

The goal of the present research was thus to extend Gonida and Cortina (2014)'s study (1) by investigating the role of three parental achievement goals (i.e., mastery, performance-approach, and performance-avoidance) rather than only two and (2) by including both mothers and adolescents rather than relying only on parent reports. In light of the important linkage between stress and controlling parenting, these relations were examined while controlling for mothers' anxiety. It was expected that performance goals would orient mothers toward the outcome while mastery goals would facilitate the adoption of a more child-centered approach. Accordingly, we postulated that parental mastery goals would facilitate parental autonomy support but that they would not be associated with controlling parenting. In contrast, performance goals, whether approach- or avoidance-oriented, should predict more controlling parenting, while preventing the adoption of more autonomy-supportive parental behaviors. These effects were expected to be independent of mothers' anxiety. Exploratory analyses were also conducted to investigate if parental goals were more closely linked to some specific parenting behaviors.

\section{Method}

\section{Participants}

Participants were 67 French-speaking mother-adolescent dyads. We recruited participants via the adolescents' high schools, which were situated in the Montreal area. Mothers were aged between 30 and 53 years $(M=42.61$ years, $S D=5.09$ years $)$ while their adolescents $(19.4 \%$ girls $)$ were aged between 13 and 16 years $(M=14.03$ years, $S D=0.96$ years). Approximately a third of the sample (35\%) had a family revenue between 30,000\$CAN and 49,999\$CAN, while $23.3 \%$ earned between 50,000\$CAN and 69,999\$CAN, $19.9 \%$ earned 70,000\$CAN or higher, and $16.7 \%$ had family revenue below 30,000\$CAN. In terms of education, $28.4 \%$ of the sample completed high school, half also obtained a pre-university or technical diploma $(50.7 \%)$, and $20.9 \%$ received a university 
degree. Most of the sample (94\%) spoke French at home while a few families spoke both French and English $(n=4)$. One mother reported Arabic as a second language in addition to French and one spoke Italian in addition to French and English.

\section{Procedure}

Mothers received a consent form and a questionnaire by mail, which they completed at home and returned in a prepaid return-envelop. The questionnaire assessed parental achievement goals, anxiety trait and demographic variables. Upon receipt of parental consent, research assistants met the adolescents at their school and invited them to complete the Perceived Parental Autonomy Support Scale. A total of sixty-seven dyads were recruited using this procedure.

Efforts were also made to increase sample size. However, only 70 mothers were recruited in this second wave of data collection; adolescents could not be recruited because visits to the school could not be planned before the end of the school year. Mothers recruited in the second wave of data collection did not differ from the others in terms of age, revenue, education level, anxiety or types of goals. Participation to this study was not compensated.

\section{Measures}

Parental achievement goals were reported by mothers using the Parental Achievement Goal Questionnaire. This scale was inspired by Elliot and McGregor (2001)'s Achievement Goal Questionnaire. It is comprised of three subscales, each assessing a specific type of goals that mothers can have for their adolescent. Specifically, parental mastery goals ( 3 items, e.g., I want my child to do his/her best in the activities he/she is involved in; $\alpha=.69$ ), performanceapproach goals ( 4 items, e.g., I try to encourage my child to finish among the first in what he/she does; $\alpha=.80$ ), and performance-avoidance goals (4 items, e.g., I do not want my child to do activities in which he/she will be less competent than others; $\alpha=.85$ ) were assessed. A three factor CFA was conducted and provided acceptable fit indices $\left(\chi^{2}(d f=39, n=127)=60.10, p<.02, \quad \chi^{2} /\right.$ $d f=1.75, \mathrm{CFI}=.95, \mathrm{NNFI}=.92, \mathrm{RMSEA}=.07[.03 /$ $.10])$. Items, factor loadings, and factor correlations are presented in Table 1.

Mothers' trait anxiety and socio-economic status (SES) were assessed as potential covariates. Mothers reported their tendency to experience anxiety in general using the 20-item trait anxiety subscale of the State-Trait Anxiety Inventory (Gauthier and Bouchard 1993; Spielberger 1983). Items were rated on a 7-point response scale ranging from "Never" (1) to "Always" (7). A sample item is "I feel nervous and restless". The trait-anxiety subscale has proven reliable and valid in past studies and yielded an excellent reliability coefficient in the present study $(\alpha=.90)$. SES was assessed by averaging the standardized scores of mothers' revenue and educational level.

Adolescents evaluated their mothers' use of autonomysupportive and controlling behaviors using the Perceived Parental Autonomy Support Scale (P-PASS; Mageau et al. 2015a). The P-PASS measures three autonomy-supportive behaviors and three controlling practices using a 4-item subscale per behavior. Autonomy-supportive behaviors are provision of choice (e.g., "My mother gave me many opportunities to make my own decisions about what I was doing"; $\alpha=.63$ ), acknowledgement of the child's feelings (e.g., "My mother was open to my thoughts and feelings even when they were different from hers"; $\alpha=.78$ ), and provision of a rationale for rules and demands (e.g., "When my mother asked me to do something, she explained why she wanted me to do it"; $\alpha=.64)$. Controlling behaviors are guilt-inducing criticisms (e.g., "My mother made me feel guilty for anything and everything"; $\alpha=.85$ ), use of threats (e.g., "When I refused to do something, my mother threatened to take away certain privileges in order to make me do it"; $\alpha=.85$ ), and performance pressures (e.g., "My mother refused to accept that I could want simply to have fun without trying to be the best"; $\alpha=.67$ ). Total scores for autonomy support and controlling parenting were obtained by averaging the relevant subscales. Reliability coefficients were high $(\alpha=.85$ for autonomy support and $\alpha=.85$ for controlling parenting). Past research shows that autonomy-supportive and controlling behaviors form two separate factors in exploratory factor analyses (Mageau et al. 2015a). Also, higher-order factor analysis showed that the six subscales load in expected ways on two higher-order factors, with three subscales loading on an autonomy-supportive secondorder factor and three subscales loading on a controlling one (Fournier et al. 2010).

\section{Data Analyses}

Correlations among mothers' trait anxiety, age and SES, their adolescent's age and gender, and maternal behaviors were first examined to identify potential covariates. Correlations among maternal goals, autonomy support and controlling parenting were then inspected, followed by the main analyses. Two hierarchical regression analyses were conducted, one for maternal autonomy support and one for controlling parenting, to investigate their relations with maternal goals while controlling for potential covariates and for the interrelations among the three goals. In a more exploratory fashion, we also conducted regression analyses to examine the relations among maternal goals and the six 
Table 1 Items, factor loadings, and factor correlations of the parental achievement goal questionnaire

\begin{tabular}{lcc}
\hline Item & Factor 1 & Factor 2 \\
\hline "I want my child to do his/her best in the activities he/she is involved in" & .73 & .66 \\
"I try to help my child get better in his/her activities" & .58 & .81 \\
"I wish that my child improves in what he/she gets involved in" & .73 \\
"I try to encourage my child to finish among the first in what he/she does" & .62 \\
"I wish that my child be better than others in the activities he/she does" & .60 \\
"I try to help my child be the best in the activities he/she is engaged in" & .91 \\
"I would like my child to excel in his/her activities" & .84 \\
"I do not want my child to do activities in which he/she will be less competent than others" & .71 \\
"I encourage my child to avoid the activities where he/she could feel inferior to others" & .55 \\
"I encourage my child to avoid activities where he/she might not be the best" & .08 \\
"I prefer that my child does not do activities where he/she may not excel” & $.53^{*}$ \\
Correlation with Factor 1 & \\
Correlation with Factor 2 & $.31^{*}$
\end{tabular}

parenting behaviors separately, controlling for potential covariates.

\section{Results}

Correlations revealed that mothers' trait anxiety was unrelated to controlling parenting but was associated with less autonomy support, $r=-.25, p<.05$. Mothers' age and SES, and their adolescent's age and gender were not significantly related to autonomy-supportive or controlling parenting. Given these results, maternal anxiety was entered as a covariate in the main regression analyses. No multicollinearity problem was detected during the analyses.

Pearson correlations among maternal goals, autonomy support and controlling parenting are presented in Table 2, along with the means and standard deviations of these variables. Correlations showed that when the common variance among the different types of goals is not taken into account, only performance-approach goals are negatively linked to maternal autonomy support, $r=-.25$, $p<.05$, suggesting that performance-approach goals may be an obstacle to adopting autonomy-supportive behaviors. There was also a positive correlation between maternal performance-approach goals and maternal performanceavoidance goals, $r=.37, p<.01$.

Maternal autonomy support and controlling parenting were submitted to hierarchical regression analyses wherein maternal anxiety was entered in a first block, followed by maternal goals (see Table 3 ). The overall model was significant for controlling parenting, $F(4,61)=2.71, p<.05$, with maternal goals explaining 14 percent of the variance above and beyond maternal anxiety. Regression coefficients showed that the less mothers reported having mastery goals $(\beta=-.31, p<.05)$ and the more they had performanceapproach goals $(\beta=.33, p<.05)$, the more their adolescents observed instances of controlling parenting. For autonomy support, the overall model was only marginal, $F(4$, $61)=2.07, p=.10$. Regression coefficients also revealed a marginal link between performance-approach goals and maternal autonomy support, $\beta=-.24, p=.09$, although this effect was accounted for by maternal anxiety as suggested by the non-significant difference in percentages of explained variance, $\Delta R^{2}=.06, F(3,61)=1.41, p=.25$.
Table 2 Means, standard deviations, and correlations for maternal goals and behaviors

\begin{tabular}{llrrrrrr}
\hline Construct & Means & $S D$ & 2 & 3 & 4 & 5 & 6 \\
\hline Maternal mastery goals & 6.12 & .91 & .21 & -.01 & -.11 & .06 & -.22 \\
Maternal performance-approach goals (2) & 3.61 & 1.36 & & $.37^{* *}$ & .21 & $-.25^{*}$ & .13 \\
Maternal performance-avoidance goals (3) & 1.90 & 0.93 & & & $.48^{* * *}$ & -.20 & -.12 \\
Trait anxiety (4) & 2.18 & 0.64 & & & $-.25^{*}$ & -.12 \\
Maternal autonomy support (5) & 5.39 & 0.97 & & & & -.18 \\
Controlling parenting (6) & 2.50 & 1.07 & & & & & \\
\hline
\end{tabular}

$* p<.05 ; * * p<.01 ; * * * p<.001$ 
Table 3 Summary of regression analyses predicting controlling parenting and autonomy support

\begin{tabular}{|c|c|c|c|c|c|c|}
\hline \multirow[t]{2}{*}{ Block } & \multicolumn{3}{|c|}{ Controlling parenting } & \multicolumn{3}{|c|}{ Autonomy support } \\
\hline & $R^{2}$ & $\Delta R^{2}$ & $\beta$ & $R^{2}$ & $\Delta R^{2}$ & $\beta$ \\
\hline 1. Anxiety & .01 & & -.13 & $.06^{*}$ & & $-.24 *$ \\
\hline 2. Anxiety & $.15^{*}$ & $.14^{*}$ & -.14 & .12 & .06 & -.18 \\
\hline Mastery goals & & & $-.31 *$ & & & .13 \\
\hline Performance approach goals & & & $.33 *$ & & & -.24 \\
\hline Performance avoidance goals & & & -.20 & & & -.04 \\
\hline
\end{tabular}

$* p<.05$
In light of the positive correlation between performanceapproach goals and maternal autonomy support and given the marginal regression coefficient linking these two variables, we explored the relations among maternal goals and the six parenting behaviors separately, controlling for maternal anxiety (see Table 4). For controlling behaviors, results showed that maternal goals predicted the use of guilt-inducing criticisms $\left(\Delta R^{2}=.16, F(3,61)=3.96\right.$, $p<.05)$ and performance pressures $\left(\Delta R^{2}=.14, F(3\right.$, $61)=3.36, p<.05)$ above and beyond maternal anxiety, but not the use of threats. Regression coefficients revealed that performance-approach goals were key in predicting performance pressures: The more mothers aimed for their child to demonstrate high performance compared to others, the more they applied pressure to achieve their goals, $\beta=.41, p<.05$. In contrast, all three goals were predictive of guilt-induction: the less mothers reported having mastery goals $(\beta=-.29, p<.05)$ or performance-avoidance goals $(\beta=-.30, p<.05)$ and the more they had performance-approach goals $(\beta=.37, p<.01)$, the more their adolescents observed instances of guilt-induction. For autonomy-supportive behaviors, results showed that maternal goals predicted perceived acknowledgement of feelings above and beyond maternal anxiety, $\Delta R^{2}=.12$, $F(3,61)=2.79, p<.05$, but not mothers' provision of rationales or choices. Regression coefficients revealed that the more mothers reported having performance-approach goals, the less their adolescents perceived that their mothers recognized and acknowledged their feelings, $\beta=-.34, p<.05$.

\section{Discussion}

Overall, results showed that the more mothers have performance-approach goals for their adolescent and the less they focus on task mastery, the more they are perceived as controlling by their adolescent. These findings replicated the link between performance goals and controlling parenting found by Gonida and Cortina (2014) and extended these results (1) by showing that this link applies to performance-approach goals in particular and (2) by documenting an additional negative link between mastery goals and controlling parenting. This study also provided a more

Table 4 Summary of exploratory regression analyses predicting individual maternal behaviors

\begin{tabular}{|c|c|c|c|c|c|c|c|c|c|c|c|c|c|c|c|c|c|c|}
\hline \multirow[t]{2}{*}{ Block } & \multicolumn{3}{|c|}{$\begin{array}{l}\text { Guilt-inducing } \\
\text { criticisms }\end{array}$} & \multicolumn{3}{|c|}{$\begin{array}{l}\text { Performance } \\
\text { pressures }\end{array}$} & \multicolumn{3}{|c|}{ Use of threats } & \multicolumn{3}{|c|}{$\begin{array}{l}\text { Acknowledgement } \\
\text { of feelings }\end{array}$} & \multicolumn{3}{|c|}{$\begin{array}{l}\text { Providing } \\
\text { rationales }\end{array}$} & \multicolumn{3}{|c|}{$\begin{array}{l}\text { Choice within } \\
\text { limits }\end{array}$} \\
\hline & $\mathrm{R}^{2}$ & $\Delta \mathrm{R}^{2}$ & $\beta$ & $\mathrm{R}^{2}$ & $\Delta \mathrm{R}^{2}$ & $\beta$ & $\mathrm{R}^{2}$ & $\Delta \mathrm{R}^{2}$ & $\beta$ & $\mathrm{R}^{2}$ & $\Delta \mathrm{R}^{2}$ & $\beta$ & $\mathrm{R}^{2}$ & $\Delta \mathrm{R}^{2}$ & $\beta$ & $\mathrm{R}^{2}$ & $\Delta \mathrm{R}^{2}$ & $\beta$ \\
\hline $\begin{array}{l}\text { 1. Maternal } \\
\text { anxiety }\end{array}$ & .01 & .01 & -.06 & .03 & & -.18 & .00 & & -.07 & .04 & & -.21 & $.08 *$ & & $-.28^{*}$ & .01 & & -.10 \\
\hline $\begin{array}{l}\text { 2. Maternal } \\
\text { anxiety }\end{array}$ & $.17 *$ & $.16^{*}$ & -.04 & $.17 *$ & $.14 *$ & -.23 & .06 & .06 & -.06 & $.16^{*}$ & $.12 *$ & -.14 & .12 & .04 & $-.22 *$ & .05 & .04 & -.09 \\
\hline Mastery goals & & & $-.29 *$ & & & -.21 & & & -.23 & & & .22 & & & .00 & & & .09 \\
\hline $\begin{array}{l}\text { Performance } \\
\text { approach } \\
\text { goals }\end{array}$ & & & $.37 *$ & & & $.41 *$ & & & .03 & & & $-.34 *$ & & & -.04 & & & -.22 \\
\hline $\begin{array}{l}\text { Performance } \\
\text { avoidance } \\
\text { goals }\end{array}$ & & & $-.30 *$ & & & -.09 & & & -.09 & & & .00 & & & -.18 & & & .09 \\
\hline
\end{tabular}

$* p<.05$ 
conservative test of these associations because key variables were assessed with different informants and while controlling for maternal anxiety. Further investigation of the relations between parental goals and specific controlling parental behaviors allowed for a more refined understanding of the linkage between parental goals and controlling parenting: Having performance-approach goals seem to be a risk factor for using guilt-inducing criticisms and performance pressures in particular. In addition, mothers who focus on task mastery and on preventing failure seem less likely to engage in guilt-induction, as perceived by their adolescents. Maternal goals did not seem to be relevant in predicting mothers' use of threats. For autonomy support, results showed that parental goals did not predict maternal autonomy support in general. However, performance-approach goals may be an obstacle to the adoption of one autonomy-supportive behavior in particular, namely the acknowledgement of feelings.

The non-significant link between mastery goals and autonomy support was unexpected given that this link had been previously observed (Gonida and Cortina 2014). It is possible that mastery goals and autonomy support are in fact related but this relation was not apparent in the present study. Whereas Gonida and Cortina (2014)'s study focused on a specific activity, i.e., doing homework, the present study evaluated goals and parenting behaviors more generally, which may have reduced the link between mastery goals and autonomy support. Yet, it is also possible that the previously observed link between mastery goals and autonomy support reported in Gonida and Cortina (2014)'s study was due to a common variance bias. The potential link between parental mastery goals and maternal autonomy support thus calls for further investigation. Another unexpected finding was that mothers' performance-avoidance goals were related negatively to guilt-induction. This finding suggests that mothers who wish to protect their adolescent from experiencing failure may be highly concerned with creating a safe environment that would not only be failure-free but also guilt-free. Future research is needed to investigate the ramifications of such protective strategies. For example, mothers with performance-avoidance goals may discourage their teenager from participating in competitions, thereby limiting potential learning experiences. Yet, they may also orient their adolescent towards more collaborative learning experiences (e.g., creativity-based activities).

The present research contributes to research on the antecedents of autonomy-supportive and controlling parenting in important ways (Deci and Ryan 1985, 2000). First, it supports Gonida and Cortina (2014)'s proposition that parental achievement goals may be important determinants of autonomy-supportive and controlling parenting. Specifically, the adoption of performance-approach goals seems to be a risk factor for controlling parenting (and for guilt-induction and performance pressures in particular), whereas focusing on mastery seems to prevent the use of controlling strategies (in the form of guilt-inductions). The fact that the observed relations were obtained while controlling for mothers' general tendency to experience anxiety and when the variables of interest were reported by different informants give strength to these findings.

Second, this research reveals that, in addition to promoting more controlling behaviors, adopting performanceapproach goals may be an obstacle to acknowledging adolescents' feelings. Recent research has found that maternal perspective taking predicts change in the use of autonomy-supportive behaviors but that there is no recursive effect (Mageau et al. 2015b). In light of these findings, it seems reasonable to suggest that performance-approach goals may limit parents' tendency to consider their adolescent's perspective, which in turn would reduce their ability to acknowledge their adolescent's feelings in addition to increasing their tendency to use controlling behaviors. The obtained pattern of relations confirms the usefulness of examining maternal behaviors separately (i.e., guilt inductions, performance pressures, threats, acknowledgement of feelings, rationales, choice), in addition to investigating more global parenting dimensions (i.e., autonomy support and controlling parenting), to elucidate how maternal goals translate into behaviors. A more refined understanding of these processes should in turn facilitate the development of more targeted and effective interventions aimed at preventing controlling parenting and promoting parental autonomy support.

This research also extends goal research in showing that people may have achievement goals for another person. Although past studies have focused mostly on goals that people have for their own achievements, research is beginning to show that in relationships people elaborate goals that concern the person with whom they are interacting and that these goals influence their behaviors toward this other person (Carbonneau and Koestner 2014; Soenens et al. 2015). The present findings, together with Gonida and Cortina (2014)'s study, confirm that parents do have goals regarding their children's achievements and that these achievement goals are associated with their parenting behaviors. This research thereby highlights the importance of considering parents' cognitions about their adolescent as these cognitions seem to guide their interpersonal behaviors. Although several authors have suggested that parental goals guide the way parents interact with their children (Dix 1992; Grusec et al. 1997), empirical research on this topic is scarce. By highlighting the usefulness of parental achievement goals in predicting parenting behaviors, the present study should stimulate additional investigations of the impact of parental achievement goals on parenting. In 
particular and using a larger sample, future research should examine the impact of parental goals on parenting while distinguishing between the six different goals proposed in Elliot et al. (2011)'s $3 \times 2$ achievement goal model.

Experimental and longitudinal work is also needed to pursue the investigation of the impact of parental goals on parenting. Although different informants were used to assess maternal goals and parenting, the design of the present study was correlational. It might be that maternal goals for their adolescent's achievements are yet another consequence of autonomy-supportive and controlling parenting. It is also possible that there are reciprocal effects where controlling parenting and performance-approach goals would fuel one another by maintaining parents' focus away from their adolescent's internal frame of reference. Studying the relations between these variables using experimental and longitudinal designs thus constitutes important research avenues. Another limitation is that our results can only apply to mothers. Although Gonida and Cortina (2014) found relations between parental goals and parenting behaviors with a sample composed of both mothers and fathers, additional research is needed to test these relations with a sample of fathers. Finally, although we controlled for maternal trait anxiety, future studies could include more specific forms of anxiety (e.g., regarding parenting or the child's future) to investigate their potential influence on the relations between parental goals and parenting.

In conclusion, understanding the reasons why some parents engage in more controlling, and less autonomysupportive, parenting is an essential step to help parents nurture children's optimal functioning and prevent important adjustment problems (see Barber 2002; Grolnick 2003; Joussemet et al. 2008a; Moreau and Mageau 2013, for reviews). This study suggests that parental performanceapproach goals are a risk factor for controlling parenting in addition to being a potential obstacle to acknowledging adolescents' feelings, a central autonomy-supportive behavior. Mastery goals are also identified as an intervention target to prevent the use of guilt-inducing criticisms. Future research is now needed to further investigate these effects with larger samples and using experimental and longitudinal designs.

Acknowledgments We thank the Social Sciences and Humanities Research Council of Canada (SSHRC) for funding this research.

\section{References}

Anderson, K. E., Lytton, H., \& Romney, D. M. (1986). Mothers' interactions with normal and conduct-disordered boys: Who affects whom? Developmental Psychology, 22, 604-609. doi:10. 1037/0012-1649.22.5.604.
Ballash, N., Leyfer, O., Buckley, A. F., \& Woodruff-Borden, J. (2006). Parental control in the etiology of anxiety. Clinical Child and Family Psychology Review, 9, 113-133. doi:10.1007/ s10567-006-0007-z.

Barber, B. K. (1996). Parental psychological control: Revisiting a neglected construct. Child Development, 67, 3296-3319. doi:10. $2307 / 1131780$.

Barber, B. K. (2002). Intrusive parenting: How psychological control affects children and adolescents. Washington, DC: American Psychological Association.

Bernier, A., Carlson, S. M., \& Whipple, N. (2010). From external regulation to self-regulation: Early parenting precursors of young children's executive functioning. Child Development, 81, 326-339. doi:10.1111/j.1467-8624.2009.01397.x.

Bronstein, P. (1994). Patterns of parent-child interaction in Mexican families: A cross-cultural perspective. International Journal of Behavioral Development, 17, 423-446. doi:10.1016/01636383\%2894\%2990034-5.

Bronstein, P., Duncan, P., D’Ari, A., Pieniadz, J., Fitzgerald, M., Abrams, C. L., \& Oh Cha, S. Y. (1996). Family and parenting behaviors predicting middle school adjustment: A longitudinal study. Family Relations: An Interdisciplinary Journal of Applied Family Studies, 45, 415-426. doi:10.2307/585171.

Carbonneau, N., \& Koestner, R. (2014). Un regard sur les processus motivationnels et le soutien à l'autonomie dans le contexte des buts pour autrui [Motivational processes and autonomy support in the context of goals for others]. Paper presented at the 36e annual conference of the Société Québécoise pour la Recherche en Psychologie (SQRP), Montréal, Québec, Canada.

Cleveland, E. S., Reese, E., \& Grolnick, W. S. (2007). Children's engagement and competence in personal recollection: Effects of parents' reminiscing goals. Journal of Experimental Child Psychology, 96, 131-149. doi:10.1016/j.jecp.2006.09.003.

Conger, K. J., Conger, R. D., \& Scaramella, L. V. (1997). Parents, siblings, psychological control, and adolescent adjustment. Journal of Adolescent Research, 12, 113-138. doi:10.1177/ 0743554897121007.

Courneya, K. S., \& McAuley, E. (1991). Perceived effectiveness of motivational strategies to enhance children's intrinsic interest in sport and physical activity. Journal of Social Behavior \& Personality, 6, 125-136.

Deci, E. L., Eghrari, H., Patrick, B. C., \& Leone, D. R. (1994). Facilitating internalization: The self-determination theory perspective. Journal of Personality, 62, 119-142. doi:10.1111/j. 1467-6494.1994.tb00797.x.

Deci, E. L., \& Ryan, R. M. (1985). Intrinsic motivation and selfdetermination in human behavior. New York: Plenum.

Deci, E. L., \& Ryan, R. M. (2000). The "what" and "why" of goal pursuits: Human needs and the self-determination of behavior. Psychological Inquiry, 11, 227-268. doi:10.1207/ S15327965PLI1104_01.

Dix, T. (1992). Parenting on behalf of the child: Empathic goals in the regulation of responsive parenting. In I. E. Sigel, A. V. McGillicudy-DeLisi, \& J. J. Goodnow (Eds.), Parental belief systems: The psychological consequences for children (2nd ed., pp. 319-346). Hillsdale, NJ: Lawrence Erlbaum Associates, Inc.

Dodge, K. A., Pettit, G. S., \& Bates, J. E. (1994). Socialization mediators of the relation between socioeconomic status and child conduct problems. Child Development, 65, 649-665. doi:10. 2307/1131407.

Downie, M., Chua, S. N., Koestner, R., Barrios, M. F., Rip, B., \& M'Birkou, S. (2007). The relations of parental autonomy support to cultural internalization and well-being of immigrants and sojourners. Cultural Diversity and Ethnic Minority Psychology, 13, 241-249. doi:10.1037/1099-9809.13.3.241. 
Dweck, C. S. (1986). Motivational processes affecting learning. American Psychologist, 41, 1040-1048. doi:10.1037/0003-066X. 41.10.1040.

Elliot, A. J. (1999). Approach and avoidance motivation and achievement goals. Educational Psychologist, 34, 169-189. doi:10.1207/s15326985ep3403_3.

Elliot, A. J., \& Church, M. A. (1997). A hierarchical model of approach and avoidance achievement motivation. Journal of Personality and Social Psychology, 72, 218-232. doi:10.1037/ 0022-3514.72.1.218.

Elliot, A. J., \& Harackiewicz, J. M. (1996). Approach and avoidance achievement goals and intrinsic motivation: A mediational analysis. Journal of Personality and Social Psychology, 70, 461-475. doi:10.1037/0022-3514.70.3.461.

Elliot, A. J., \& McGregor, H. A. (2001). A $2 \times 2$ achievement goal framework. Journal of Personality and Social Psychology, 80, 501-519. doi:10.1037/0022-3514.80.3.501.

Elliot, A. J., Murayama, K., \& Pekrun, R. (2011). A $3 \times 2$ achievement goal model. Journal of Educational Psychology, 103, 632-648. doi:10.1037/a0023952.

Elliot, A. J., \& Thrash, T. M. (2004). The intergenerational transmission of fear of failure. Personality and Social Psychology Bulletin, 30, 957-971. doi:10.1177/0146167203262024.

Fabes, R. A., Leonard, S. A., Kupanoff, K., \& Martin, C. L. (2001). Parental coping with children's negative emotions: Relations with children's emotional and social responding. Child Development, 72, 907-920. doi:10.1111/1467-8624.00323.

Fauber, R., Forehand, R., Thomas, A. M., \& Wierson, M. (1990). A mediational model of the impact of marital conflict on adolescent adjustment in intact and divorced families: The role of disrupted parenting. Child Development, 61, 1112-1123. doi:10.2307/ 1130879.

Flett, G. L., Hewitt, P. L., Oliver, J. M., \& Macdonald, S. (2002). Perfectionism in children and their parents: A developmental analysis. In G. L. Flett \& P. L. Hewitt (Eds.), Perfectionism: Theory, research, and treatment (pp. 89-132). Washington, DC: American Psychological Association.

Fournier, S., Nolet, K., Scavone, G., Dupré, M.-P., Ranger, F., Koestner, R., et al. (2010). Construction and validation of the Perceived Parental Autonomy Support Scale (P-PASS). Paper presented at the 4th international conference on self-determination theory, Ghent, Belgium.

Garber, J., Robinson, N. S., \& Valentiner, D. (1997). The relation between parenting and adolescent depression: Self-worth as a mediator. Journal of Adolescent Research, 12, 12-33. doi:10. 1177/0743554897121003.

Gauthier, J., \& Bouchard, S. (1993). Adaptation canadienne-française de la forme révisée du "State-Trait Anxiety Inventory" de Spielberger. Revue canadienne des sciences du comportement, 25, 559-578. doi:10.1037/h0078881.

Gonida, E. N., \& Cortina, K. S. (2014). Parental involvement in homework: Relations with parent and student achievementrelated motivational beliefs and achievement. British Journal of Educational Psychology, 84, 376-396. doi:10.1111/bjep.12039.

Goodnow, J. J., \& Collins, W. A. (1990). Development according to parents: The nature, sources and consequences of parents' ideas. New York: Psychology Press.

Grolnick, W. S. (2003). The psychology of parental control: How well-meant parenting backfires. Mahwah, NJ: Lawrence Erlbaum Associates.

Grolnick, W. S., \& Pomerantz, E. M. (2009). Issues and challenges in studying parental control: Toward a new conceptualization. Child Development Perspectives, 3, 165-170. doi:10.1111/j. 1750-8606.2009.00099.x.

Grolnick, W. S., Price, C. E., Beiswenger, K. L., \& Sauck, C. C. (2007). Evaluative pressure in mothers: Effects of situation, maternal, and child characteristics on autonomy supportive versus controlling behavior. Developmental Psychology, 43, 991-1002. doi:10.1037/0012-1649.43.4.991.

Grolnick, W. S., \& Ryan, R. M. (1989). Parent styles associated with children's self-regulation and competence in school. Journal of Educational Psychology, 81, 143-154. doi:10.1037/0022-0663. 81.2.143.

Grolnick, W. S., Weiss, L., McKenzie, L., \& Wrightman, J. (1996). Contextual, cognitive, and adolescent factors associated with parenting in adolescence. Journal of Youth and Adolescence, 25, $33-54$.

Grusec, J. E., Rudy, D., \& Martini, T. (1997). Parenting cognitions and child outcomes: An overview and implications for children's internalization of values. In J. E. Grusec \& L. Kuczynski (Eds.), Parenting and children's internalization of values: A handbook of contemporary theory (pp. 259-282). Hoboken, NJ: Wiley.

Gurland, S. T., \& Grolnick, W. S. (2005). Perceived threat, controlling parenting, and children's achievement orientations. Motivation and Emotion, 29, 103-121. doi:10.1007/s11031-0057956-2.

Herman, M. R., Dornbusch, S. M., Herron, M. C., \& Herting, J. R. (1997). The influence of family regulation, connection, and psychological autonomy on six measures of adolescent functioning. Journal of Adolescent Research, 12, 34-67. doi:10.1177/ 0743554897121004.

Joussemet, M., Koestner, R., Lekes, N., \& Houlfort, N. (2004). Introducing uninteresting tasks to children: A comparison of the effects of rewards and autonomy support. Journal of Personality, 72, 139-166. doi:10.1111/j.0022-3506.2004.00259.x.

Joussemet, M., Koestner, R., Lekes, N., \& Landry, R. (2005). A longitudinal study of the relationship of maternal autonomy support to children's adjustment and achievement in school. Journal of Personality, 73, 1215-1235. doi:10.1111/j.14676494.2005.00347.x.

Joussemet, M., Landry, R., \& Koestner, R. (2008a). A self-determination theory perspective on parenting. Canadian Psychology, 49, 194-200. doi:10.1037/a0012754.

Joussemet, M., Mageau, G. A., \& Koestner, R. (2014). Promoting optimal parenting and children's mental health: A preliminary evaluation of the how-to parenting program. Journal of Child and Family Studies, 23, 949-964. doi:10.1007/s10826-0139751-0.

Joussemet, M., Vitaro, F., Barker, E. D., Côté, S., Nagin, D. S., Zoccolillo, M., \& Tremblay, R. E. (2008b). Controlling parenting and physical aggression during elementary school. Child Development, 79, 411-425. doi:10.1111/j.1467-8624.2007. 01133.x.

Koestner, R., Ryan, R. M., Bernieri, F., \& Holt, K. (1984). Setting limits on children's behavior: The differential effects of controlling vs. informational styles on intrinsic motivation and creativity. Journal of Personality, 52, 233-248. doi:10.1111/j. 1467-6494.1984.tb00879.x.

Kuczynski, L. (1984). Socialization goals and mother-child interaction: Strategies for long-term and short-term compliance. Developmental Psychology, 20, 1061-1073. doi:10.1037/00121649.20.6.1061.

Landry, R., Whipple, N., Mageau, G., Joussemet, M., Koestner, R., DiDio, L., \& Haga, S. M. (2008). Trust in organismic development, autonomy support, and adaptation among mothers and their children. Motivation and Emotion, 332, 173-188. doi:10.1007/s11031-008-9092-2.

Leroy, N., Bressoux, P., Sarrazin, P., \& Trouilloud, D. (2007). Impact of teachers' implicit theories and perceived pressures on the establishment of an autonomy supportive climate. European Journal of Psychology of Education, 22, 529-545. doi:10.1007/ BF03173470. 
Lessard, J., Mageau, G. A., Joussemet, M., \& Koestner, R. (2015). The impact of rule enforcement strategies and interpersonal climates on mothers' and children's compliance and internalization beliefs. Department of psychology, Université de Montréal, Montreal, Canada (in preparation).

Maccoby, E. E., \& Martin, J. A. (1983). Socialization in the context of the family: Parent-child interaction. In P. H. Mussen \& E. M. Hetherington (Eds.), Handbook of child psychology: Vol. 4. Socialization, personality, and social development (4th ed.). New York: Wiley.

Mageau, G. A., Ranger, F., Joussemet, M., Koestner, R., Moreau, E., \& Forest, J. (2015a). Validation of the Perceived Parental Autonomy Support Scale (P-PASS). Canadian Journal of Behavioural Science, 47, 251-262. doi:10.1037/a0039325.

Mageau, G. A., Sherman, A., Grusec, J. E., Koestner, R., \& Bureau, J. S. (2015b). Recursive effects of maternal perspective taking and child knowledge on autonomy support. Department of psychology, Université de Montréal, Montreal, Canada (in preparation).

McCranie, E. W., \& Bass, J. D. (1984). Childhood family antecedents of dependency and self-criticism: Implications for depression. Journal of Abnormal Psychology, 93, 3-8. doi:10.1037/0021843X.93.1.3.

McLoyd, V. C. (1989). Socialization and development in a changing economy: The effects of paternal job and income loss on children. American Psychologist, 44, 293-302.

Miller, S. M., Birnbaum, A., \& Durbin, D. (1990). Etiologic perspectives on depression in childhood. In M. Lewis \& S. M. Miller (Eds.), Handbook of developmental psychopathology (pp. 311-325). New York, NY: Plenum Press.

Moller, A. C., \& Elliot, A. J. (2006). The $2 \times 2$ achievement goal framework: An overview of empirical research. In A. V. Mitel (Ed.), Focus on educational psychology (pp. 307-326). Hauppauge, NY: Nova Science.

Moreau, E., \& Mageau, G. A. (2013). Conséquences et corrélats associés au soutien de l'autonomie dans divers domaines de vie [The outcomes and correlates of autonomy support in various life domains]. Psychologie Francaise, 58, 195-227. doi:10.1016/ j.psfr.2013.03.003.

Nicholls, J. G. (1984). Achievement motivation: Conceptions of ability, subjective experience, task choice, and performance. Psychological Review, 91, 328-346. doi:10.1037/0033-295X.91. 3.328.

Niemiec, C. P., Lynch, M. F., Vansteenkiste, M., Bernstein, J., Deci, E. L., \& Ryan, R. M. (2006). The antecedents and consequences of autonomous self-regulation for college: A self-determination theory perspective on socialization. Journal of Adolescence, 29, 761-775. doi:10.1016/j.adolescence.2005.11.009.

Pettit, G. S., Laird, R. D., Dodge, K. A., Bates, J. E., \& Criss, M. M. (2001). Antecedents and behavior-problem outcomes of parental monitoring and psychological control in early adolescence. Child Development, 72, 583-598. doi:10.1111/1467-8624.00298.

Pomerantz, E. M., \& Eaton, M. M. (2001). Maternal intrusive support in the academic context: Transactional socialization processes. Developmental Psychology, 37, 174. doi:10.1037/0012-1649.37. 2.174 .

Prinzie, P., van der Sluis, C. M., de Haan, A. D., \& Dekovic, M. (2010). The mediational role of parenting on the longitudinal relation between child personality and externalizing behavior. Journal of Personality, 78, 1301-1323. doi:10.1111/j.14676494.2010.00651.x.

Rapee, R. M. (1997). Potential role of childrearing practices in the development of anxiety and depression. Clinical Psychology Review, 17, 47-67. doi:10.1016/S0272-7358\%2896\%2900040-2.
Sheldon, K. M., Abad, N., \& Omoile, J. (2009). Testing selfdetermination theory via Nigerian and Indian adolescents. International Journal of Behavioral Development, 33, 451-459. doi:10.1177/0165025409340095.

Silk, J. S., Morris, A. S., Kanaya, T., \& Steinberg, L. (2003). Psychological control and autonomy granting: Opposite ends of a continuum or distinct constructs? Journal of Research on Adolescence, 13, 113-128. doi:10.1111/1532-7795.1301004.

Soenens, B., Luyckx, K., Vansteenkiste, M., Duriez, B., \& Goossens, L. (2008a). Clarifying the link between parental psychological control and adolescents' depressive symptoms: Reciprocal versus unidirectional models. Merrill-Palmer Quarterly, 54, 411-444. doi:10.1353/mpq.0.0005.

Soenens, B., Luyckx, K., Vansteenkiste, M., Luyten, P., Duriez, B., \& Goossens, L. (2008b). Maladaptive perfectionism as an intervening variable between psychological control and adolescent depressive symptoms: A three-wave longitudinal study. Journal of Family Psychology, 22, 465-474. doi:10.1037/0893-3200.22. 3.465 .

Soenens, B., \& Vansteenkiste, M. (2010). A theoretical upgrade of the concept of parental psychological control: Proposing new insights on the basis of self-determination theory. Developmental Review, 30, 74-99. doi:10.1016/j.dr.2009.11.001.

Soenens, B., Vansteenkiste, M., Duriez, B., \& Goossens, L. (2006). In search of the sources of psychologically controlling parenting: The role of parental separation anxiety and parental maladaptive perfectionism. Journal of Research on Adolescence, 16, 539-559. doi:10.1111/j.1532-7795.2006.00507.x.

Soenens, B., Vansteenkiste, M., Lens, W., Luyckx, K., Goossens, L., Beyers, W., \& Ryan, R. M. (2007). Conceptualizing parental autonomy support: Adolescent perceptions of promotion of independence versus promotion of volitional functioning. Developmental Psychology, 43, 633-646. doi:10.1037/0012-1649.43. 3.633 .

Soenens, B., Wuyts, D., Vansteenkiste, M., Mageau, G. A., \& Brenning, K. M. (2015). Raising trophy kids: Do mothers with contingent self-esteem prioritize extrinsic goals over intrinsic goals in their child-rearing? Journal of Adolescence, 42, 40-49. doi:10.1016/j.adolescence.2015.04.001.

Spielberger, C. D. (1983). Manual for the State-Trait Anxiety Inventory. Palo Alto, California: Consulting Psychologist Press.

Stebbings, J., Taylor, I. M., \& Spray, C. M. (2011). Antecedents of perceived coach autonomy supportive and controlling behaviors: Coach psychological need satisfaction and well-being. Journal of Sport \& Exercise Psychology, 33, 255-272.

Whipple, N., Bernier, A., \& Mageau, G. A. (2011). Broadening the study of infant security of attachment: Maternal autonomysupport in the context of infant exploration. Social Development, 20,17-32. doi:10.1111/j.1467-9507.2010.00574.x.

Williams, G. C., Cox, E. M., Hedberg, V. A., \& Deci, E. L. (2000). Extrinsic life goals and health-risk behaviors in adolescents. Journal of Applied Social Psychology, 30, 1756-1771. doi:10. 1111/j.1559-1816.2000.tb02466.x.

Wood, J. J., McLeod, B. D., Sigman, M., Hwang, W.-C., \& Chu, B. C. (2003). Parenting and childhood anxiety: Theory, empirical findings, and future directions. Journal of Child Psychology and Psychiatry, 44, 134-151. doi:10.1111/1469-7610.00106.

Zussman, U. J. (1980). Situational determinants of parental behavior: Effects of competing cognitive activity. Child Development, 51, 792-800. 